\title{
La profundidad de la apariencia: el vestido en el debate entre el arte y el diseño
}

\author{
The depth of appearance: \\ clothing in the debate \\ between art and design
}

\author{
Claudia Fernández Silva (Colombia) \\ claudia.fernandez@upb.edu.co \\ Universidad Pontificia Bolivariana
}

\section{Resumen}

El presente artículo hace parte de las reflexiones alrededor de la investigación de la tesis doctoral titulada El vestido en la creación del cuerpo: una aproximación desde el diseño y la creación, adelantada en el Doctorado en Diseño y Creación de la Universidad de Caldas. Dicha investigación tiene por objetivo proponer una manera de entender y estudiar la relación entre el diseño y el vestido a partir de la acción creadora. De acuerdo con esta premisa, indagaremos sobre uno de los problemas

\begin{abstract}
This article is part of the reflections on the research of the doctoral thesis entitled "Clothing in the creation of the body: an approach from design and creation", presented in the PhD in Design and Creation from the University of Caldas. This research is to propose a way to understand and study the relationship between design and clothing from the creative action. According to this premise, we inquired about one of the problems in the general history of design as an area of knowledge, that is, their differences and
\end{abstract}

FECHA DE RECEPCIÓN: 14 de septiembre de 2012 FECHA DE REVISIÓN: 23 de noviembre de 2012 APROBACIÓN:
Para Citar este artículo / to Cite this ARTicle Fernández, C. (2013). La profundidad de la apariencia: el vestido en el debate entre el arte y el diseño. Poliantea, IX (16), pp. 129-150. 
por el que atraviesa la historia general del diseño como área de conocimiento, esto es, sus diferencias y proximidades con el arte, cuyos argumentos centrales han dado forma a la actual concepción del vestido como un objeto ligado a la apariencia, que dificulta su análisis crítico desde la perspectiva disciplinar del diseño. The profoundness of appearance, the dress in the debate between art and design

Palabras clave: diseño, arte, vestido, utilidad, apariencia. proximity to art, whose central arguments have shaped the current design of clothing as an object linked to the appearance, which makes difficult the critical analysis from the disciplinary perspective of design.

Keywords: design, art, clothing, utility, appearance. 


\section{La profundidad de la apariencia: el vestido en el debate entre el arte y el diseño}

Claudia Fernández Silva (Colombia)

Diseñadora industrial, Universidad Pontificia Bolivariana. Maestra de Artes en Diseño, Creative Academy (Milán, Italia). Candidata a doctora en Diseño y Creación, Universidad de Caldas. Docente, investigadora y coordinadora del Área de Proyecto en Diseño de Vestuario de la Universidad Pontificia Bolivariana.

\section{Introducción}

Descubrí lo siguiente y lo comuniqué al mundo: la evolución cultural equivale a la eliminación del ornamento del objeto usual. Adolf Loos

La relativamente reciente creación de Diseño de Vestuario en la Universidad Pontificia Bolivariana como primer programa académico que aborda un estudio profesional del vestido desde el seno de la disciplina ha implicado una revisión y reflexión sobre las maneras de abordarlo y comprenderlo. Tarea que no ha sido fácil, pues, como se expone en estas páginas, la supuesta única función estetizante del vestido lo ha llevado a ser comprendido solo a través de la mirada del fenómeno de cambio regular llamado moda, lo que ha limitado su estudio y comprensión.

En el presente artículo, se busca, a través de la indagación de las principales líneas de argumentación sobre la relación entre arte y diseño, comprender las maneras en que un objeto llega a ser calificado o descalificado para ser considerado objeto del diseño a partir de su alto nivel estético. La hipótesis es que allí se encuentran algunas de las razones del distanciamiento teórico que desde la disciplina se le ha dado al vestido. Se recogerá para 
este rastreo la posición de algunos autores y teorías que han contribuido a distanciar o acercar estas áreas del conocimiento y que abonan los terrenos para que hoy se considere el diseño como una disciplina diferenciada.

En algunos momentos de la historia general del diseño y el arte, las posiciones estéticas han servido como argumento para desvirtuar la función operativa de los objetos de diseño, que, despojados de su utilidad en pos de una afectación de los sentidos, solo pueden ser considerados objetos del arte.

El vestido como objeto particular de estudio y recientemente de práctica académica ${ }^{l}$ atraviesa una situación similar al ser considerado por muchos un objeto aparente en lugar de un objeto ligado a la apariencia, con toda la profundidad que esto puede involucrar. La supuesta única función estetizante del vestido lo ha llevado a ser comprendido solo a través de la mirada del fenómeno de cambio regular llamado moda, a la cual se la relaciona con la

\footnotetext{
El diseño de vestuario como programa académico profesional se inicia en Colombia en 2001, dándole inicio a un estudio del vestido como objeto del diseño más allá del fenómeno de cambio regular llamado moda.
}

feminidad y la banalidad, un imaginario que toca por igual a personas del común y académicos de diferentes áreas del conocimiento, incluido el diseño. Esta consideración ha traído consigo algunas dificultades en el momento de abordar investigaciones que toman por objeto de estudio al vestido desde una perspectiva disciplinar, pero, si el diseño es la disciplina de los objetos útiles y el vestido es el objeto cotidiano más utilizado, ¿ dónde radica la dificultad para aprehenderlo en toda su complejidad y no solo como un objeto ornamental?

La hipótesis presentada en este artículo se centra en que los argumentos construidos a lo largo de los años, que tenían como fin validar la disciplina y establecerla como un campo de conocimiento independiente y diferenciado del arte, sentaron las bases para la limitada concepción actual del vestido. Dichos argumentos fueron construyendo un discurso alrededor de la utilidad como característica fundamental de los objetos de diseño, llegando por momentos a descalificar todo aquello que se presentase como demasiado estético y meramente comunicativo. El vestido, al igual que otros objetos, puede llegar 
por momentos, en determinados contextos y en ciertas ocasiones de uso, a superponer su función secundaria sobre su función primaria $o$ básica, que provoca que los determinismos de los límites entre arte y diseño se posen sobre él.

Para la validación de esta hipótesis, se rastreará la posición de algunos autores y teorías que han contribuido a distanciar o acercar estas áreas del conocimiento a partir de dos asuntos problematizadores: la apariencia y la utilidad. Hablar de apariencia nos guiará hacia cuestionamientos acerca de los aspectos del exterior de las cosas, considerados en el imaginario común como superficiales, ligados a la percepción sensible del mundo material, que abordan para su desarrollo procesos de estilización más que procesos proyectuales $\mathrm{y}$, por lo tanto, más cercanos al arte. Hablar de utilidad llevará, por su parte, a revisar cómo el mundo de los objetos cotidianos se margina del mundo del arte, cómo se dividen y diferencian los significados de los términos arte y técnica y, posteriormente, arte, artesanía y diseño, para establecer la frontera entre la resolución de necesidades del mundo instrumental corporal y la exaltación del espíritu.
Para dilucidar de qué forma estas disertaciones afectan la pregunta por la particularidad de nuestro objeto de estudio, se observan algunas de las líneas argumentales que se derivan de lo que se ha podido concluir, como son los discursos más fuertes alrededor de estos dos conceptos: la polaridad entre los instrumental y lo simbólico y la profundidad de la apariencia, para finalizar con el vestido en el debate entre el arte y el diseño.

\section{La polaridad: entre lo instrumental y lo simbólico}

La pregunta por lo que hay entre nosotros y las cosas ha evolucionado con el pasar de las épocas a la par con las preguntas acerca del mundo que nos rodea y los intentos por comprenderlo, medirlo y domesticarlo. Para hacer de ese mundo un mundo propio, los seres humanos han creado toda una suerte de extensiones de sí que les permitan desentrañar sus más profundos secretos, $y$, en esta tarea, explicarse también a sí mismos su razón de ser y su existencia.

En ciertos momentos de la historia, los objetos que nacieron de un mismo tronco, como expresión pura de la relación de los hombres 
con su entorno, se bifurcaron por medio de la razón y la técnica en ramas que definían una acción diferenciada sobre dicha expresión: los objetos para el hacer, por un lado, los objetos para sentir y comunicar, por otro. Esta misma división trajo como consecuencia que la acción humana se parcializara entre la creación de instrumentos, de los cuales se ocuparían los artesanos y más tarde los diseñadores, y la creación de objetos simbólicos de los cuales se ocuparían los artistas. Polarización que tendría como consecuencia la formación de disciplinas con saberes diferenciados, como el arte y el diseño.

Las cosas, que en un antes vagaron por la vida sin nombres específicos, pudiendo ser obras de la naturaleza u obras de los hombres, se definirán con el tiempo por su finalidad. Los objetos utilitarios serán despojados del aura del arte en el Renacimiento, pero más tarde serán también los artistas quienes los llamen a participar de un mundo más humano tras la llegada de la máquina. El siglo XX se entregará a la razón científica e intentará de nuevo encasillarlos en categorías bien diferenciadas para estudiar sus procesos de creación bajo la mirada del método, en una búsqueda por alejar la intuición como motor de la creación. Las últimas décadas antes del cambio de milenio entregarán la pregunta sobre la posibilidad de la existencia de un modo de pensar propio para la proyectación de objetos que, en lugar de excluir ramas del saber, las integre en la potenciación de un objeto que pueda tener en cuenta que los seres humanos no concebimos nuestra relación con el mundo desde lo instrumental o lo simbólico, sino desde ambos.

\section{La polaridad vista desde el objeto}

\author{
No hay objeto si no es con \\ respecto a un sujeto (que \\ observa, aísla, define, piensa), \\ $y$ no hay sujeto si no es con \\ respecto a un ambiente objetivo \\ que le permite reconocerse, \\ definirse, pensarse, etc. \\ Pero también existir. \\ EDGAR MORÍN
}

En su texto Diseño y teoría de los objetos, Raimonda Riccini (2008) nos recuerda sobre la soberana indiferencia que nuestra cultura ha mostrado a lo largo de los años frente a los objetos. Enuncia cómo en la filosofía la cosa se vuelve objeto solo en cuanto remite a un sujeto, esto es, a 
un creador o a un utilizador. Como bien explica, "la cosa se convierte en objeto si y solo si se asume como una finalidad, como un objetivo, una intencionalidad que presupone, por lo tanto, siempre un sujeto" (p. 292). La autora plantea cómo esta dicotomía entre sujeto y objeto ${ }^{2}$, que deduce es la razón del distanciamiento hacia las cosas concretas, se encuentra de manera explícita en el arte al marginar de la representación a los objetos durante siglos, referidos solo a través de su significado simbólico y no desde un ordenamiento casual del hombre y su entorno.

Si se fija la mirada ahora sobre las definiciones que algunos autores le han brindado al objeto de diseño, se observa cómo la relación sujetoobjeto ha sido comprendida mayormente como la probabilidad que

2 La etimología de la palabra objeto proviene de estar "enfrente"; se dice en latín objacere, verbo del que se deriva ob-jicere, cuyo participio es ob-jetum. A todas las realidades que están enfrente del hombre y pueden ser analizadas por este sin comprometer su propio ser, los filósofos modernos las llamaron objetos. Este concepto de objeto comprende tres aspectos: el aspecto de resistencia al sujeto, el carácter material del objeto y la idea de permanencia, ligada a la de inercia (necesitar de otro, externo al ser, para moverse). Son realidades objetivadas las que pueden ser medidas, pesadas, agarradas con la mano, situadas en el espacio, dominadas y manejadas (Cano, 2010, p. 143). el segundo le brinda al primero de extenderse más allá de sus posibilidades biológicas. Así es como encontramos términos como prótesis e interfaces para explicar su operatividad. Gui Bonsiepe en Del objeto a la interface (1998) dice que la interface hace posible la acción eficaz, y que, además, es el tema central del diseño.

A través de ella se pueden aclarar las diferencias entre ingeniería y diseño como disciplinas proyectuales [...], el diseñador industrial se concentra en los fenómenos de uso y de funcionalidad, es decir, en la integración de los artefactos con la cultura cotidiana. Su centro de interés se centra en la eficiencia sociocultural (1998, p. 23).

De todo lo anterior se deduce, entonces, que el objeto de diseño posee una relación especial de proximidad con el cuerpo humano, mientras que los objetos del arte fueron por muchos años ligados a la contemplación, concepto que ha venido evolucionando desde los performances de los movimientos de vanguardia en los inicios del siglo XX hasta la introducción de los nuevos medios en el campo de las artes.

A partir de estas premisas, se puede afirmar hasta este punto que la 
característica que prevalece para distinguir un objeto del diseño por sobre cualquier cosa y sin importar su especificidad es la utilidad. A este respecto, Yves Zimmermann en "El arte es arte el diseño es diseño" (2003) recuerda que "todos los diseños crean productos diferentes, pero tienen en común que son fruto del diseño y también que todos ellos son utilitarios, cuya característica esencial es que sirven para conseguir un fin concreto" (p. 60). El discurso de los fines o del por qué y para qué del objeto será la diferencia primordial entre la producción del arte y el diseño.

\section{La polaridad vista desde los creadores de objetos: hacia una retrospectiva de la polaridad}

Se indagará ahora de dónde proviene esta marcada diferenciación entre los objetos del diseño y el arte a partir de su valor utilitario, y por qué se convierte en un argumento para definir un campo de estudio especializado.

En Pioneros del diseño moderno (2003), Nikolaus Pevsner narra cómo la noción de utilidad estableció un distanciamiento entre la acción creadora y los creadores de objetos. En la Edad Media, dice el autor, "el artista era a la vez un artesano orgulloso de ejecutar cualquier encargo con el máximo de habilidad" (p. 21), pero más tarde, durante el Renacimiento, los artistas se autodenominaron sacerdotes, seres superiores, portadores de un mensaje sublime. Tan magna tarea no les permitiría, por lo tanto, ocuparse ya del mundo de los objetos domésticos y utilitarios, formulando a partir de allí una escisión entre la labor del artesano y la labor del artista que permanecería diferenciada hasta finales del siglo XVIII cuando condiciones contextuales, ligadas al desarrollo industrial, promovieron un pensamiento crítico que, en cabeza de algunos artistas, integraría de nuevo el mundo del arte con el mundo de los objetos cotidianos. Ruskin, Morris y los seguidores del movimiento de artes y oficios condenarían las vanidades de los artistas de los siglos anteriores y reivindicarían el poder evocador del arte en la vida y las experiencias de los hombres comunes. Ludistas en su naturaleza, estos artistas ven en la máquina una degradación del ideal creador humano y como respuesta promueven que los objetos sean dignificados por el trabajo directo de la mano sobre la materia. De esta forma, los objetos del arte y los objetos utilitarios no son más dos asuntos 
diversos y excluyentes y es el artista y posteriormente también el arquitecto, los llamados a unificar las dimensiones instrumentales y simbólicas de la acción transformadora del mundo.

En 1972, Adolf Loos en Ornamento $y$ delito reflexiona acerca de esta marcada separación, y plantea cómo antes y después la sociedad estaba convencida de que el artista hacía cosas sin necesidad ni sentido de lo práctico. Ahonda, además, sobre el criterio de valor que emerge cuando lo utilitario se vuelve una medida para definir, por así decirlo, el grado de artisticidad de un objeto cuando enuncia:

[...] de todo ello resulta evidente, además, que también las obras de arte aplicadas a la vida práctica, o bien usadas en la vida práctica, quedan en cierta medida desvalorizadas. Solo cuando se liberen del peso de la eventual valoración práctica (es decir, cuando sean colocadas en un museo), y no antes, se reconocerá su valor auténtico (artístico) (Loos, 1972, p. 152).

Pero lo que resulta aún más interesante para nuestros días es su convicción de que la mencionada polaridad debe ser superada, reconociendo que la creación de los objetos está atravesada por asuntos más allá de sus finalidades utilitarias.

A continuación, se rastreará el momento en que los diseñadores pasan a ser los artífices de la creación de objetos y qué implicaciones trae la definición de su práctica. "Solo la división del trabajo y la emergencia de las condiciones de producción de una sociedad industrial hicieron que fuera necesario diferenciar la actividad del diseño y dejarlo a cargo de especialistas" (Rinker, 2008, p. 248). Las instituciones educativas tuvieron también una importante contribución en la formulación y definición de la práctica del diseñador. Partiendo de las intenciones de la Deutscher Werkbund ${ }^{3}$ hasta la Bauhaus que, aunque definitiva en los antecedentes que definen la práctica del diseñador, como institución de formación artística, artesanal e industrial, no esclareció verdaderamente una diferencia tajante entre estas prácticas creadoras, tal vez, porque, precisamente, su deseo era el de unificarlas y, por lo tanto, no establece

3 Deutscher Werkbund fue una asociación mixta de arquitectos, artistas e industriales, fundada en 1907 en Múnich, por el arquitecto, escritor y diplomático alemán Hermann Muthesius. 
qué hace del diseño una práctica diferenciada. Por su parte, la Hochschule für Gestaltung de Ulm no solo definió las actividades del diseñador, sino que claramente se distanció de los programas con orientación en arte, y de la mano de Tomás Maldonado aplicó una nueva filosofía científica basada en el operacionismo científico.

Como vemos, la inclusión de la acción del diseño como práctica creadora trajo consigo un nuevo distanciamiento con el arte, ya no solo desde la concepción misma de los objetos, que ahora son observados científicamente, sino también desde su enseñanza, la cual es abordada metodológicamente hacia la configuración del proyecto. No obstante, las fronteras trazadas entre ambos siguieron y siguen siendo difusas desde los años de las primeras escuelas.

\section{La polaridad vista desde la disciplina}

Cuando se sitúa en el seno de la disciplina misma, se encuentran también fuertes argumentos de autores que, a lo largo de su historia, han intentado aclarar la relación entre arte y diseño a partir de la definición de sus prácticas, la cual se centra de manera recurrente en la utilidad como leitmotiv desde el cual se pueden establecer toda suerte de diferencias y divergencias.

Desde finales de los años cincuenta, Maldonado había denunciado como un asunto problemático el predominio de la estética en el trabajo de diseño.

El factor estético constituye meramente un factor entre otros con los cuales el diseño puede operar, pero no es ni el principal ni el predominante. Junto a él también está el factor productivo, el constructivo, el económico y quizás también el factor simbólico. El diseño industrial no es un arte y el diseñador no es necesariamente un artista (Maldonado, citado por Rinker, 2008, p. 249).

André Ricard (1986) define el diseño como la disciplina creativa experta en formas útiles. Presenta la manera en que los teóricos tomaron como modelo de referencia la producción industrial para distinguir el diseño del arte y de las artes aplicadas y para darle al diseño como nueva disciplina credibilidad dentro de los industriales y los empresarios.

Otra perspectiva de esta polaridad entre lo instrumental y lo simbólico o entre utilidad y apariencia nos viene dada de la mano de Victor Margolin en Design discourse (1989) 
cuando pone de manifiesto la manera en que esta afecta no solo las definiciones de arte y diseño, sino el interior mismo de la disciplina, que provoca subdivisiones alrededor de sus objetos de estudio. Si bien no habla específicamente de la utilidad, tal vez, por considerarse ya de plano como una característica del diseño, denuncia una separación a partir de consideraciones artísticas y tecnológicas:

We presently divide design in the narrowest sense into discrete forms of practice such as industrial design, graphic design, interior design, or fashion design. This tends to the most part to separate more artistically oriented ways of designing from those connected to engineering or computer science, which are technologically based ${ }^{4}$ (Margolin, 1989, p. 4).

El argumento de Margolin ratifica, en parte, la hipótesis presentada. Estas orientaciones dentro del diseño mismo pueden haber contribuido a que el objeto vestimentario

4 Actualmente dividimos al Diseño en su sentido más estrecho al interior de diferentes formas de práctica como el diseño industrial, el diseño gráfico, o el diseño de moda. Lo cual tiende en gran medida a separar las formas del diseño más artísticamente orientadas de aquellas conectadas con las ciencias de la ingeniería o la computación, las cuales se fundamentan en la tecnología. sea comprendido como pura expresividad, estrechando así su campo de análisis y excluyendo otras dimensiones de la relación hombre-objeto.

\section{La profundidad de la apariencia}

El lugar de la experiencia lo ocupa ahora el de la apariencia.

Otl Aicher

Pero no solo es el arte que visto desde la perspectiva del diseño fue catalogado como inútil, referido claro está a los momentos en que se le mide con la vara de la creación de objetos utilitarios, sino el mismo diseño el que, como lo explica Bonsiepe (1998), visto desde la perspectiva de la ingeniería, no es más que maquillaje, estilización o apariencia, un acabado para la verdadera esencia de lo útil contenida en los objetos técnicos.

En contraste con las acusaciones de que el diseño es pura cosmética, se presentan algunas voces que intentan explicar la importancia y las razones de ser de la apariencia de los objetos, demostrando que son muchas las condiciones que aportan a ese aspecto final de los productos. Petra Kellner (2008) enuncia varios factores como los presupuestos perceptivos, los hechos históricos, las condiciones sociales y culturales, los 
estándares técnicos, las imágenes sociales rectoras, las normas estéticas y dominantes. Todas, afirma la autora, son influencias que pueden cambiar un producto independiente de su función práctica.

André Ricard responderá, a su vez, a la acusación de diseño como simple make-up, explicando cómo

[...] al dotar de su forma a un objeto no es cuestión de maquillar sus defectos para que ofrezca una falsa imagen de sí mismo. De lo que se trata es de dotarlo, de base, de una estructura formal coherente que exprese lo que es, de quién es, a quién se destina y que sea un testimonio de su tiempo (2000, p. 149).

Esta expresión es entendida desde Buchanan (1989) como arte retórico, diferente de un arte del adorno, a través del cual se envuelve todo un argumento de diseño sin importar el tipo de objeto producido.

Con este recorrido por diversos argumentos y autores acerca de la polaridad entre apariencia y utilidad, se presentaron las bases para dilucidar los criterios a partir de los cuales la disciplina del diseño juzga y estudia a sus objetos, que son los mismos criterios que recaen sobre el vestido en el momento de ser observado desde una perspectiva disciplinar. A continuación, se verán algunos aspectos que recaen sobre su particularidad como objeto, con el fin de terminar de conocer o reconocer por qué ha caído en el imaginario de la banalidad.

\section{El vestido en el debate entre el arte y el diseño}

Como se ha podido observar, los discursos alrededor de la relación de los conceptos de apariencia y utilidad han sentado los paradigmas de nuestra actual visión frente a lo que se considera o no un objeto del diseño, al mismo tiempo que evidencian la lucha interna de este último para constituirse como un campo del saber diferenciado de aquel que le dio origen. Como se planteó en la hipótesis, la necesidad constante del diseño de definir sus límites a partir de las causas finales de su acción puede haber ocasionado la actitud recelosa de los académicos frente a un abordaje disciplinar del vestido. Esta actitud es evidente en los diversos foros, seminarios y congresos alrededor de la reflexión e investigación del diseño en el país, donde la participación de temáticas alrededor del vestido es escasa y, en ocasiones, inexistente. Se verá ahora cómo los argumentos estudiados 
acerca de la utilidad y la apariencia de los objetos se posan sobre el vestido y condicionan su percepción actual y sus dificultades para asimilarlo en relación con las ideas de utilidad impuestas por el diseño.

\section{La moda no es útil}

El vestido, si bien es un objeto de los más cotidianos que han podido existir, y por su función dentro de la historia de la humanidad se le puede considerar de los más utilitarios, desde hace varios siglos ha sido emparentado con el fenómeno de cambio regular llamado moda. Pero la moda no es un fenómeno exclusivo del vestido ni tampoco puede situarse su acción dentro de un objeto particular.

Cuando al vestuario se lo relaciona con el fenómeno moda entra en los turbios terrenos de la condena social; como bien se sabe a la moda se la sataniza y se le culpa de muchos vicios humanos ligados a su sed de cambio. El objeto vestimentario es solo la punta más visible del ritmo frenético de la moda; todos los objetos de diseño, al igual que las expresiones artísticas y los comportamientos, en últimas, todas las dinámicas sociales, están permeados por ella, dado que su estrategia radica en crear un sistema de valores y distribuirlos a gran escala. En Occidente, y cada vez más fuera de él, la moda estructura la mayor parte de nuestra experiencia con los objetos, las personas y el mundo.

Baudrillard explica muy bien esta situación:

[...] la condena a la moda es por su futilidad; en nuestra cultura, encadenada al principio de utilidad, la futilidad representa la transgresión, la violencia, y la moda es condenada por ese poder que hay en ella de signo puro, que no significa nada (1980, p. 107).

La moda no es útil en ese sentido ofrecido por el diseño, y el objeto que está tocado por ella, como enuncia Aicher (1997), caerá en el "útil inútil", donde el beneficio de la notoriedad ha suplantado el beneficio del uso, del styling en lugar del diseño.

Pareciera ser, entonces, que el vestido tocado por la moda o mejor aún el vestido de moda no puede considerarse un objeto de diseño, pues, su utilidad no es lo bastante evidente. Algunos autores distinguen tres términos diferentes para abordar el vestido como objeto en relación con la moda: moda indumentaria o moda del vestir 
(Saulquin, 2010; Scopa, 2005), no moda y antimoda (Polhemus y Proctor, 1978; Saulquin, 2010). El primero se refiere a la producción de prendas con fabricación y difusión masiva que conlleva un sistema integrado por la alta costura, la confección seriada, el prêt-à-porter y otras sutiles gradaciones diferenciales, y lo define como un subsistema dentro del sistema general de la indumentaria; el segundo se refiere al vestido estable y de carácter fijo, que indica pertenencia y la capacidad de ser intercambiable, a la indumentaria profesional e institucional, a los uniformes; por último, el vestido de la antimoda se refiere

[...] al vestido como medio de expresar la oposición a los valores centrales de la sociedad en una etapa determinada. Esta protesta, hecha vestimenta, permite algunas veces comunicar un estilo de vida alternativo, tal es el caso de la vestimenta hippie, mientras la moda oficial genere anticuerpos que la atacan para neutralizarla (Saulquin, 2010, p. 71).

A cada uno de estos tipos de vestido se le puede, entonces, asignar una utilidad en relación con el fenómeno. La del vestido de moda será la economía, la del vestido de la no moda será la pertenencia y la del vestido de la antimoda será la expresión de la oposición de valores. Todas, por tratarse de un objeto de uso tan íntimo, parten y repercuten en el cuerpo, desde lo simbólico, pero también desde lo instrumental.

\section{Las funciones del vestir: comunicar, significar}

De todos los objetos de nuestra cultura material se ha dicho que poseen, a grandes rasgos, dos funciones: la primaria es aquella para lo cual fue creado, en el caso del vestido sería cubrir el cuerpo; la secundaria sería aquella comunicativa o simbólica con la cual se puede designar pertenencia a un grupo o estatus dentro de una sociedad determinada. Al estudiar los orígenes del vestido suele deducirse que su función secundaria resulta imperativa, ya que, contrariamente a las primeras teorías sobre la aparición del vestido, que lo sitúan como protección frente a la intemperie, las razones mágicas y simbólicas dominan la práctica vestimentaria de los primeros humanos.

Sin embargo, en el caso particular del vestido resulta difícil hablar de una distinción radical entre lo instrumental y lo simbólico o entre utilidad y apariencia porque, como 
explica Nicola Squicciarino en $E l$ vestido habla: consideraciones psicosociológicas sobre la indumentaria (1990), al referirse a la producción de objetos creados para protegerse de los espíritus, las primeras manifestaciones artísticas tenían fines prácticos y relacionados con la magia más que fines estéticos. En referencia directa al vestido, el autor cita a Wilhelm Wundt cuando dice:

[...] los ornamentos, el tatuaje, etc., son sobre todo instrumentos mágicos y como tales se empleaban en las necesidades más urgentes a las que el hombre no puede hacer frente por sí solo, como la protección contra enfermedades y la suerte en la caza o en la guerra (citado por Squicciarino, 1990, p. 44);

de esta manera, el vestido evidencia, por lo menos en sus inicios, una clara función práctica e instrumental, no simbólica y mucho menos estética.

Patrizia Calefato en The clothed body (2004) analiza el esquema funcionalista utilizado por el semiólogo Pëtr Bogatyrëv en 1937 para estudiar el vestuario tradicional en Monrovia, con el cual identificó una serie de funciones dentro del vestir, como la práctica, estética, mágica y ritual. Para Bogatyrëv, el más mínimo detalle nos permite reconocer la función a la cual corresponde el vestido, como el vestido de luto que alude a una función ritual, la falda de rayas de una chica a una función social o el vestido rojo de un niño para protegerlo de los hechizos malignos a una función mágica. Este análisis funcional, para Calefato, pone en primer plano la significancia simbólica de la ropa y la sitúa como un signo que al ser usado satisface funciones específicas que pueden coexistir o traslaparse en el mismo aspecto del vestido; de igual manera, explica cómo operaría la función secundaría en este caso: "[...] when the dominant function is particularly strong, it neutralizes the others: for instance, the aesthetic overrides the practical function when the body is subjected to deformations or lacerations" 5 (2004, p. 15).

Sin embargo, para esta autora, la aproximación de Bogatyrëv es bastante reduccionista y la compara con la función fática de Jakobson (1963), al indicar que los signos

5 Cuando la función dominante es particularmente fuerte, neutraliza las otras: por ejemplo, la función estética anula la práctica cuando el cuerpo está sometido a deformaciones o laceraciones. 
están puestos solamente en la ropa, actuando como una suerte de lenguaje no verbal donde se excluye la relación presente entre el cuerpo y el vestido.

En la contemporaneidad, el vestido frente a un fenómeno de cambio regular, como la moda, ha adquirido diversas funciones que se refieren, principalmente, a su valor de signo dentro de una cultura. Significar adhesión o rechazo a un sistema de valores o significar pertenencia a una institución tienen como finalidad ser ubicados como cuerpos dentro del escenario social. A este respecto, André Ricard (1986) habla de cómo significar también tiene una finalidad útil, de otro rango, pero con una función muy definida.

Hay objetos que sirven como auxiliares de tareas manuales e intelectuales; otros para satisfacer, de modo sutil, nuestra sensibilidad, para manifestar nuestra adscripción a determinado grupo étnico o cultural. Los unos cubren necesidad prácticas; los otros, las no menos importantes necesidades rituales de afirmación personal, de comunicación con los demás, o de integración social (p. 202).

Para Susana Saulquin, sin embargo, desde el vestido se puede también hablar de la existencia de una función pura, la cual está presente en la indumentaria profesional. En ella, dice la autora,

[...] no se puede hablar de inspiración en modelos, ya que, al ser función pura, carecen [de] variables combinatorias. El elemento que la organiza es su habilidad funcional para formar un sistema significativo, un todo que le otorga sentido (2010, p. 97).

Como se vio, el vestido, al igual que otros objetos, enfrenta las mismas distinciones y confusiones que desde la teoría del diseño le darían su permiso de entrada como objeto de este. Cada uno de los argumentos expuestos lleva a entender que sí posee una utilidad, una funcionalidad; sin embargo, su valor utilitario, en algunas ocasiones, está puesto precisamente en el punto problematizador del debate entre arte y diseño: la atención sobre la apariencia donde el diseño acusado en algunos momentos de ser pura cosmética ha respondido con argumentaciones sobre la profundidad de la apariencia aduciendo que no hay gratuidad en ella. Pero para el vestido este punto se vuelve especialmente problemático, ya que la pregunta por la apariencia no se queda en el objeto, 
sino que se traslada al cuerpo del portador.

\section{Vestido y apariencia}

Abrumados por el sentimiento casi universal de la imposibilidad de "cambiar el mundo", los individuos cambian aquello que está en su poder: sus propios cuerpos.

V. VAle y Andrea Juno

Los papeles de la apariencia permiten identificarnos, adherirnos, incluirnos y excluirnos de unos consensos socioculturales que determinan lo que se entiende por común a todos y que nos involucra como seres sociales. El cuerpo escenificado vive y actúa en un espacio determinado, y es desde ese habitar donde se configuran sus maneras de presentarse ante el otro; en las sociedades contemporáneas este espacio es el espacio urbano y el ciberespacio, pero este último tiene otras implicaciones desde el concepto de cuerpo que no es de interés abordar por el momento.

Susana Saulquin, en La muerte de la moda, un día después (2010), realiza una revisión del vestido en la época preindustrial e industrial brindando los antecedentes para comprenderlo como un vehículo transformador de la propia imagen.
Con la llegada de la moda entre los años 1350 y 1370 - según el consenso de varios autores, entre ellos Lipovetsky (1990), Elias (1987), Saulquin (2010) - hasta el final de la Revolución Industrial en 1860, la imagen personal se transformaba de acuerdo con una lógica de imitación de los signos de clase. Con la finalidad de apropiarse de la imagen construida por la nobleza, cuenta la autora, el vestido representaba para la ascendente burguesía la posibilidad de apropiarse de las fuentes de poder que la sustentaban; más tarde, en los comienzos de la sociedad industrial,

[...] para que esta maquinaria infernal pudiera comenzar a funcionar de manera eficiente, era necesario que el imaginario social considerara al vestido como el fetiche transformador de la propia imagen, y por ende de la posición social. Convertido en herramienta de consagración, permitía sostener la ficción de acceder y pertenecer al grupo referencial, a lo otro, a lo que se necesitaba creer superior (Saulquin, 2010, p. 83).

En el futuro, dice la autora, cuya tesis se basa en que la moda como el sistema que se conoce perecerá frente al cambio de valores de nuestra época, esta condición del vestido será decisiva: 
$\mathrm{Al}$ alterarse la jerarquía de los valores, cambia también la índole de las relaciones sociales, y por ende la manera como las personas se visualizan y se muestran a los demás. La transformación de la imagen de sí mismo y de su conexión con el otro va a configurar y a impulsar el proyecto de un nuevo vestido, de una nueva manera de comunicar. Se perfila una nueva forma de representar el espacio circundante, los lazos con el otro y el propio cuerpo (Saulquin, 2010, p. 74).

La apariencia en el vestido, con su capacidad de trascender hasta el cuerpo del portador, no podría ser entendida, por lo tanto, como pura cosmética. Las implicaciones de las decisiones que se toman sobre los cuerpos a partir del vestido determinan el papel social, haciendo que lo que se comprende como simple función estética tenga trascendencia en las vidas de los seres humanos.

Se brindarán, por último, dos perspectivas que servirán para concluir las argumentaciones sobre el papel del vestido en el debate entre arte y diseño, indagando, por un lado, si el vestido frente a la importancia que brinda a la apariencia podría ser entendido como un objeto del arte y, por otro, si esa exagerada función estetizante le permite ser un objeto del diseño.

\section{El vestido entre la obra de arte y la estética prosaica}

Como ya se ha explorado, la función simbólica y estética en el vestido es predominante no solo como función secundaria que se superpone sobre la primaria, sino que en sí misma es sinónimo de utilidad. Si bien este sentido de utilidad resulta, a veces, insuficiente dentro de la teoría del diseño, pensarlo como un objeto del arte sería aún más desconcertante, pues, como se ha enunciado, se trata de un objeto de uso cotidiano.

Susana Saulquin expone la posibilidad de existencia de un vestido arte en el futuro, fruto del reordenamiento de las pautas de la indumentaria en la sociedad de la información o cibernética, desligado del principio de rentabilidad de la marca, donde el creador podrá, entonces, recuperar su nombre propio como hacedor de una obra única; en este escenario, el diseñador podrá ser llamado, con justicia, un creador de obras de arte: “[...] al producir esculturas textiles que podrán prescindir o no del soporte del cuerpo, como también de las variables que lo condicionan" (2010, p. 95). En esta reflexión reposa, sin duda, un asunto fundamental que 
permite determinarlo como fuera del diseño, y es esa posibilidad de prescindir del soporte del cuerpo, o jugar con un cuerpo artificial a la manera de los surrealistas; más allá de cuán fuerte sea o no la relación entre apariencia y utilidad, un vestido sin cuerpo es un vestido del arte.

El vestido como objeto cotidiano, a diferencia del vestido obra, plantea la urgencia de ser practicado; su estética no es poética o artística, sino prosaica.

En Prosaica, introducción a la estética de lo cotidiano (1994), Katya Mandoki establece una diferencia entre hablar de estética desde el arte y desde la vida cotidiana. Estos planteamientos ayudan a comprender cómo cuando se habla del vestido en términos de objeto estético a lo que se hace referencia es a "aquello en relación con lo cual el sujeto, en tanto sujeto estético, establece relaciones por medio de su facultad de sensibilidad" (Mandoki, 1994, p. 91). Del mismo modo, la autora advierte sobre el peligro de considerar la estética como algo restringido a las obras de arte o referido a lo bello. La estética se propone "como disciplina que se ocupa del análisis y las investigaciones de las relaciones que establece el hombre con su contexto social, conceptual y objetual en términos de su facultad de sensibilidad" (p. 89), y la prosaica será, entonces, la teorización de ese proceso estético enfocado en sus manifestaciones cotidianas.

En la prosaica como teoría de la sensibilidad cotidiana el otro es siempre autor, no autor literario, sino autor de mi presencia estética en el mundo, en un momento dado, desde un ángulo dado, el del otro (p. 88).

Desde esta perspectiva, el vestido es el encargado de completar la experiencia estética por medio de la cual somos percibidos y reconocidos como cuerpos en los espacios de intercambio social.

Aicher (1997) habla, a inicios de los noventa, de un relevo del viejo concepto de clases económicas caracterizadas por rasgos distintivos de orden primario: la paga, el salario, el honorario, el ingreso mensual, por el de clases estéticas, donde su señal característica es la estética elegida. Como matiz interesante para este debate centrado en lo estético frente a lo útil, reconoce la existencia de una estética de lo impráctico, de lo sustraído a toda finalidad, de lo inmotivado, de lo carente de función. Esta es, dice el autor, la estética 
que asume el hombre exquisito, el que tiene autoridad, ya que puede permitirse vestir lo inútil mientras los demás visten lo útil y lo práctico.

Tanto el concepto de clases estéticas, el cual plantea una división social que ya no está más en los evidentes signos de poder económico, sino en las elecciones estéticas, como el de prosaica como estética de la vida cotidiana, nos acercan a la noción del vestido como objeto que, con su capacidad de transformar la propia imagen en el uso cotidiano, dinamiza la vida social de los seres humanos, les da sentido e identidad. Su sentido estético se torna, pues, altamente utilitario en el momento de definirnos como personas frente a la mirada del otro.

Después de este recorrido por diferentes posiciones teóricas, se puede decir con certeza que el vestido como cualquier otro objeto de la cultura material requiere, desde la perspectiva del diseño, ser pensado desde sus múltiples dimensiones. La polaridad entre lo estético y lo utilitario ha sido leída para este objeto desde los terrenos del fenómeno de cambio regular llamado moda que, como lo explica Susana Saulquin, se había acostumbrado durante la cultura de masas a trabajar con los aspectos estético-psicológicos dirigidos por una sociedad interesada en el consumo. Desde ahora y en adelante, diversas tensiones contemporáneas están modelando estos imaginarios puestos sobre el vestido y, en general, sobre todos los objetos de la cultura material, que se redefinen a partir de otras polaridades, como lo analógico y lo virtual, lo real y lo simulado, lo material e inmaterial. Adicional a esto, los textiles, ahora dotados con propiedades nacidas de los avances de la nanotecnología y la miniaturización, plantean una prospectiva del vestido desde el uso, que reconsidera al cuerpo como esencia de la creación.

Para concluir, el vestido ha sido medido con la vara de la polaridad entre lo útil y lo estético, pero ya no se trata solo de que el diseño lo considere más útil y menos estético para que lo acoja en su seno, sino que el diseño mismo avance más allá de los determinismos de sus definiciones en mundo cambiante.

\section{Referencias}

Aicher, O. (1997). El mundo como proyecto. Barcelona: Gustavo Gili.

Baudrillard, J. (1980). El intercambio simbólico y la muerte. Barcelona: Monte Ávila Editores. 
Bonsiepe, G. (1998). Del objeto a la interface: mutaciones del diseño. Buenos Aires: Infinito.

Bonsiepe, G. y Fernández, S. (2008). Historia del diseño en América Latina y el Caribe: industrialización y comunicación visual para la autonomía. São Paulo: Blücher.

Buchanan, R. (1989). Declaration by design: rethoric, argument, and demonstration in design practice. En Margolin, V. (ed.). Design discourse: history, theory, criticism (pp. 91-109). Chicago: The University of Chicago Press.

Calefato, P. (2004). The clothed body. Nueva York: Berg.

Cano, C. M. (2010). Biopolítica y ciberespacio, reflexión sobre el uso que los jóvenes skinheads, emos y góticos hacen del ciberespacio y de su estética corporal (Tesis de maestría inédita). Universidad de Antioquia, Medellín, Colombia.

Jakobson, R. (1963). Linguistics and poetics. Massachusetts Institute of Technology.

Kellner, P. (2008). El lenguaje de los productos. En Bonsiepe, G. y Fernández, S. (ed.). Historia del diseño en América Latina y el Caribe: industrialización y comunicación visual para la autonomía (pp. 256262). São Paulo: Blücher.

Krippendorff, K. (2006). The semantic turn, a new foundation for design. Boca Ratón: Taylor \& Francis.

Lipovetsky, G. (1990). El imperio de lo efímero. Barcelona: Anagrama.

Loos, A. (1972). Ornamento y delito y otros escritos. Barcelona: Gustavo Gili.

Mandoki, K. (1994). Prosaica, introducción a la estética de lo cotidiano. México DF: Grijalbo.

Margolin, V. (1989). Design discourse: history, theory, criticism. Chicago: The University of Chicago Press.

Martín Juez, F. (2002). Contribuciones para una antropología del proyecto. Barcelona: Gedisa.

Pevsner, N. (2003). Pioneros del diseño moderno. Buenos Aires: Infinito.

Polhemus, T. y Proctor, L. (1978). Fashion \& anti-fashion: anthropology of clothing and adornment. Londres: Thames \& Hudson.

Rams, D. (1989). Omit the unimportant. En Margolin, V. (ed.). 
Design discourse: history, theory, visual para la autonomía (pp. 292criticism (pp. 111-171). Chicago: 300). São Paulo: Blücher.

The University of Chicago Press.

Ricard, A. (1986). Hablando de diseño: un modo de entender lo útil. Barcelona: Hogar del Libro.

Ricard, A. (2000). La aventura creativa: las raíces del diseño. Barcelona: Ariel.

Saulquin, S. (2010). La muerte de la moda, un día después. Buenos Aires: Paidós.

Scopa, O. (2005). Nostálgicos de aristocracia: el siglo xx a través de la moda, el arte y la sociedad. Madrid: Taller de Mario Muchnik.

Rinker, D. (2008). El diseño de proSquicciarino, N. (1990). El vestido ductos no es arte. En Bonsiepe, G.y Fernández, S. (ed.). Historia del diseño en América Latina y el Caribe: industrialización y comunicación visual para la autonomía (pp. 248256). São Paulo: Blücher.

Riccini, R. (2008). Diseño y teoría de los objetos. En Bonsiepe, G. y Fernández, S. (ed.). Historia del diseño en América Latina y el Caribe: habla: consideraciones psico-sociológicas sobre la indumentaria. Madrid: Cátedra.

Wick, R. (1986). Pedagogía de la Bauhaus. Madrid: Alianza.

Zimmermann, Y. (2003). El arte es arte, el diseño es diseño. En Calvera, A. (ed.). Arte ¿? Diseño (pp. 3157). Barcelona: Gustavo Gili. industrialización y comunicación 